\title{
DESAIN DAN SIMULASI MESIN PERAJANG CENGKEH DENGAN SISTEM PISAU PUTAR
}

\author{
Sarwan Ulwi \\ Program Studi Teknik Mesin \\ Universitas Muria Kudus \\ Email : 201654055@std.umk.ac.id \\ Masruki Kabib \\ Program Studi Teknik Mesin \\ Universitas Muria Kudus \\ Email: masruki.kabib@umk.ac.id \\ Akhmad Zidni Hudaya \\ Program Studi Teknik Mesin \\ Universitas Muria Kudus \\ Email:akhmad.zidni@umk.ac.id
}

\begin{abstract}
ABSTRAK
Desain mesin perajang cengkeh guna untuk menyederhanakan peralatan mesin produksi, dikenal dengan istilah teknologi tepat guna. Sering sekali perajangan cengkeh dilakukan secara manual, yaitu dengan tenaga manusia. Penelitian ini bertujuan mendesain dan mensimulasikan mesin perajang cengkeh dengan kapasitas $50 \mathrm{Kg} / \mathrm{jam}$ dengan bantuan pendorong menggunakan sistem pneumatik dan menghasilkan rajangan cengkeh dengan ukuran $0,1-0,2 \mathrm{~mm}$, Metode perancangan yang dilakukan adalah observasi lapangan,studi literatur, analisa kebutuhan mesin perajang, konsep desain mesin perajang, prinsip kerja, keunggulan, kelemahan,perhitungan dan mensimulasikan kekuatan rangka pada mesin perajang menggunakan metode elemen hingga. Hasil penelitian ini adalah desain mesin perajang cengkeh yang mampu menghasilkan rajangan cengkeh yang baik beserta mampu merajang dengan kapasitas 50kg/jam. Dimensi mesin panjang $1200 \mathrm{~mm}$, lebar $500 \mathrm{~mm}$ serta menggunakan penggerak motor listrik $1 \mathrm{HP}$ dan dari hasil perhitungan secara teoritis tegangan von mises pada rangka mesin perajang cengkeh sebesar 46,89 $\mathrm{MPa}$ dan secara simulasi tegangan von mises sebesar $49,05 \mathrm{MPa}$ jadi selisish antara perhitungan teoritis dan simulasi sebesar $4,40 \%$
\end{abstract}

Kata Kunci: Cengkeh, Perajang Cengkeh, pisau putar

\begin{abstract}
The design of the clove chopper machine to simplify production machine tools is known as appropriate technology. Very often clove chopping is done manually, by means of human labor. The objective of research is to design and simulate a clove chopper machine with a capacity of 50 $\mathrm{kg} /$ hour with the help of a pusher using a pneumatic system and to produce chopped cloves with a size of $0.1-0.2 \mathrm{~mm}$. The design method used is field observation, literature study, analysis of machine requirements. chopper, chopper machine design concept, working principles, advantages, weaknesses, calculations and simulating frame strength on chopper machines using finite element method. The results of this research was a clove chopper machine design that is capable of producing good chopped cloves and is capable of chopping with a capacity of 50kg / hour. The
\end{abstract}


dimensions of the machine was $1200 \mathrm{~mm}$ long, $500 \mathrm{~mm}$ wide and use an electric motor drive of 1 HP and from the theoretical calculation results the von Mises voltage on the clove chopper machine frame is $46.89 \mathrm{MPa}$ and simulated the von Mises stress is $49.05 \mathrm{MPa}$ so the difference between theoretical calculations and simulation of $4.40 \%$

\section{Keywords: Cloves, Clove Chopper, rotary knife}

\section{PENDAHULUAN}

Tanaman cengkeh (Eugenia carryophyllus) merupakan tanaman perkebunan/industri yang banyak ditemukan di kawasan timur Indonesia misalnya di Sulawesi Utara. Tanaman cengkeh mempunyai sifat yang khas karena semua bagian pohon mengandung minyak, mulai dari akar, batang, daun sampai bunga [1].

Kesejahteraan masyarakat khususnya bidang industri kecil perlu ditingkatkan,maka perlu meningkatkan sarana dan peralatan yang berhubungan dengan proses pengolahan mesin perajang cengkeh. Dalam industr kecil menengah masih menggunakan cara manual yaitu dengan diguntung atau ditumbuk, dalam proses ini memakan banyak waktu dan hasil rajangan cengkeh juga kurang baik [2].

Semakin berkembangnya teknologi telah dilakukan perancangan suatu mesin pencacah cengkeh dengan kapasitas $5 \mathrm{~kg} / \mathrm{jam}$ menggunakan 1 buah rol yang dipasang horizontal untuk mencacah cengkeh. Desain ini menunjukkan gerakan rol yang di lengkapi dengan pisau untuk melakukan gerak pemotongan [3].

Mesin perajang daun tembakau ini diharapkan bisa merajang daun tembakau dengan cepat dan lebih efektif serta memberi keamanan kepada operator mesin, Sistem transmisi pada mesin perajang daun tembakau ini diharapkan mampu menurunkan kecepatanwal dari motor listrik sebesar 1400 rpm menjadi kecepatan akhir sebesar 350 rpm. Transmisi yang digunakan mesin perajang daun tembakau ini menggunakan puli dan gear sprocket. Pada transmisi pertama puli yang digunakan menggunakan perbandingan $1: 4[4]$.

Analisis dengan metode elemen hingga telah di lakukan terhadap frame untuk menopang beban, analisa ini menggunakan metode elemen hingga. Hasilnya menunjukkan tegangan yang paling besar terjadi pada daerah penompang bearing dibawah piringan dan pully penggerak [5].

Analisa dengan metode elemen hingga juga telah di lakukan untuk menganalisis tegangan yang terjadi pada screw, hasilnya menunjukkan sudu screw menerima beban paling besar, hal ini disebabkan pada screw menerima beban yang paling besar untuk mendorong material[6].

Analisis tegangan pada rangka mesin pres batako juga telah di lakukan dengan metode elemen hingga, Hasilnya menunjukkan tegangan von mises yang paling besar terjadi pada tumpuan rangka pengungkit. Pada rangka ini menahan beban untuk menghasilkan gaya tekan untuk melalkukan pengepresan [7].

Tujuan penelitian ini adalah untuk merancang dan menganalisa tegangan von mises, dan displacement pada rangka mesin perajang cengkeh dengan kapasitas 50 $\mathrm{kg} / \mathrm{jam}$. Analisa tersebut dilakukan dengan metode elemen hingga menggunakan software autodesk inventor 2019 [8]. 


\section{METODOLOGI PENELITIAN}

Desain mesin perajang cengkeh yang dibuat meliputi beberapa tahapan yang terlihat seperti pada Gambar 1. Secara garis besar tahapan dimulai dari studi literatur, membuat konsep desain, desain perancangan,perhitungan dan simulasi

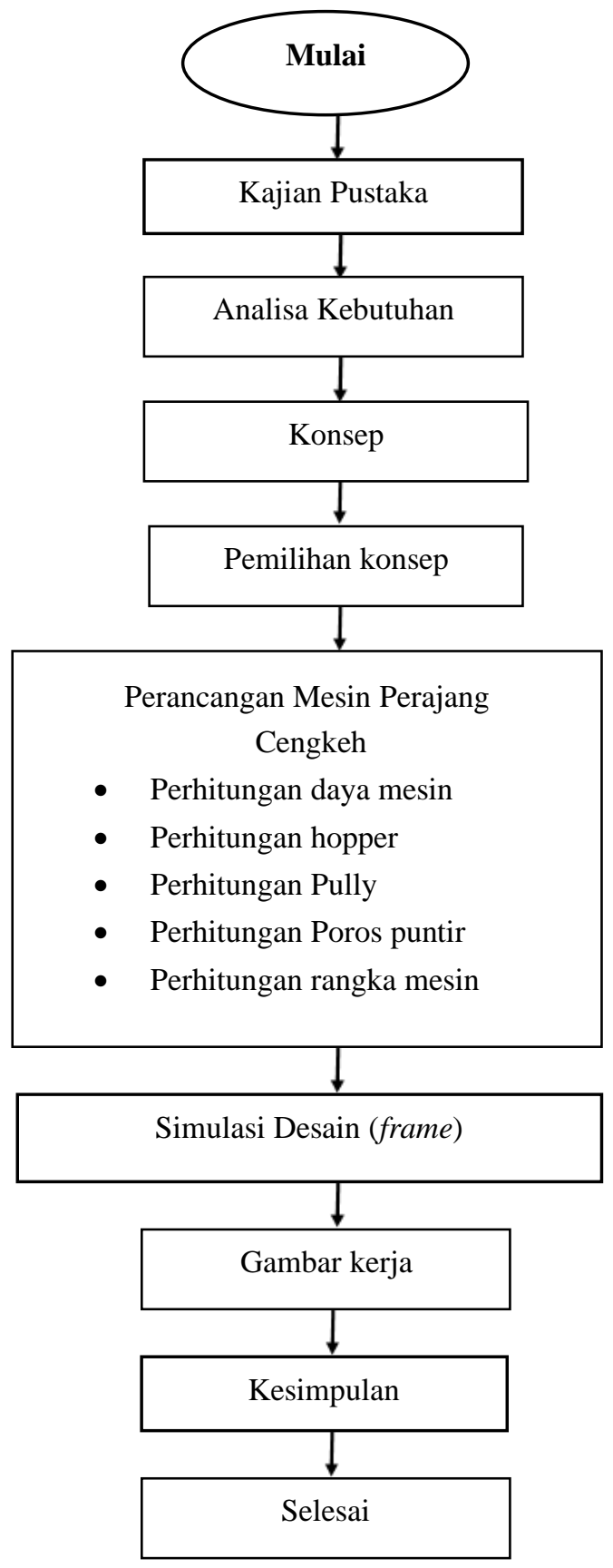

Gambar 1. Diagram alir desain mesin perajang cengkeh 
Desain mesin perajang cengkeh dengan pisau putar ini akan dilakukan dengan beberapa tahap seperti diagram alir di atas sebagai berikut:

1. Studi Literatur.

Studi literatur meliputi : pencarian berupa jurnal dan skripsi-skripsi yang sudah pernah dibuat dan terkait dengan desain mesin perajang cengkeh.

2. Analisa Kebutuhan

Analisa kebutuhan : menyesuaikan kebutuhan dalam aspek teknik, aspek manufaktur, aspek perakitan, aspek perawatan, aspek lingkungan.

3. Konsep Desain.

Melakukan proses konsep desain dengan memberikan gambaran perbandingan dari alat yang di bangun dengan suatu pengartian mesin perajang cengkeh.

4. Pemilihan konsep desain.

Melakukan proses pemilihan konsep desain dari beberapa konsep desain yang telah di sajikan, dengan mempertimbangkan segi keefektifitas sistem kerjannya.

5. Perancangan.

Perhitungan daya motor, perhitungan V-belt,perhitungan poros punter, Perhitungan hopper, perhitungan pully, perhitungan rangka mesin.

6. Simulasi.

Melakukan simulasi dan menganalisa kekuatan frame dengan menggunakan metode lemen hingga.

\section{HASIL DAN PEMBAHASAN}

3.1 Analisa kebutuhan sistem

Adapun beberapa langkah analisa kebutuhan pada perancangan mesin perajang cengkeh:

1. Aspek Teknik

Pada perancangan mesin perajang cengkeh ini harus mampu merajang cengkeh dengan kapasitas 50kg/jam, dengan menggunakan empat mata pisau untuk merajang dan menggunakan pendorong dengan sistem pneumatic. Sehingga dapat menghasilkan cengkeh dengan ukuran $0,1-0,2 \mathrm{~mm}$.

2. Aspek Manufaktur Kontruksi pembuatan rangka dengan menggunakan material baja L st37 dan proses pengerjaan menggunakan CNC bubut untuk poros pully, Las SMAW untuk rangka.

3. Aspek Perakitan

Mesin perajang cengkeh dengan kapasitas 50kg/jam ini dirancang dengan kemudahan dalam proses assembly pada komponen mesin perancang cengkeh. Pada mesin perajang cengkeh dengan kapasitas $50 \mathrm{~kg} / \mathrm{jam}$ ini spertpat komponen mudah ditemukan dan diganti.

4. Aspek Perawatan

Mesin perajang cengkeh dengan kapasitas $50 \mathrm{~kg} / \mathrm{jam}$ ini dirancang dnegan komponen sperpart yang banyak diperjual belikan sehingga memudahkan dalam perawatan.

5. Aspek Lingkungan

Mesin perajang cengkeh dengan kapasitas $50 \mathrm{~kg} / \mathrm{jam}$ dirancang agar dapat digunakan tanpa mencemari lingkungan dan dapat membuat pekerjaan lebih efektif dan efisien.

6. Aspek Ekonomi

Mesin perajang ini dapat dirancang oleh bengkel kecil ataupun dapat digunakan dalam home industri karena suku cadang yang murah dan mudah didapat. 
3.2 Desain Mesin Perajang Cengkeh.

Pemilihan desain ini dilakukan melalui beberapa tahapan veriabel-variabel tertentu dan pertimbangan dari nerbagai konsep desain, maka dari hasil pertimbangan tersebut berhasil terpilih konsep desain mesin perajang cengkeh seperti gambar 2.

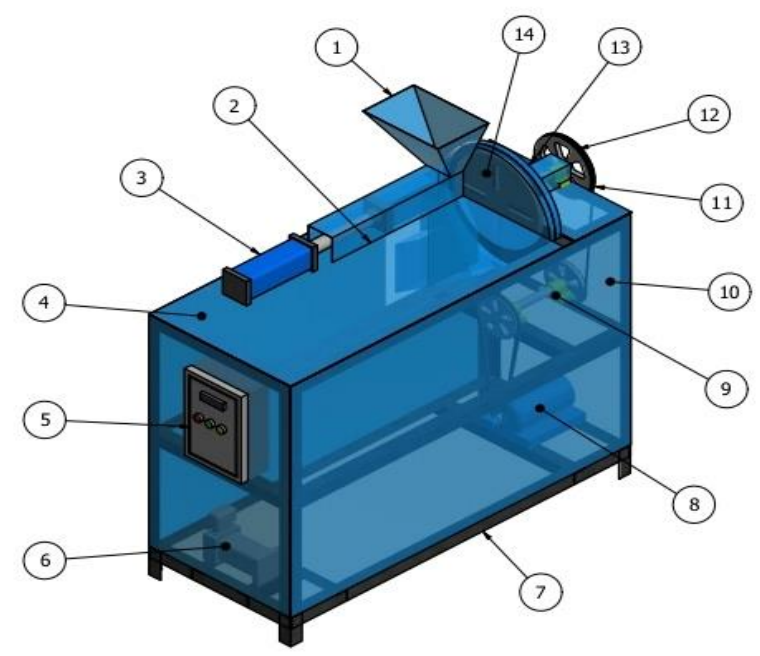

Gambar 2. Desain mesin perajang cengkeh dengan kapasitas 50kg/jam menggunakan sistem pneumatic.

Pada gambar 2 menunjukan bagian-bagian dari mesin perajang cengkeh yang terdiri dari (1)rangka utama, (2)pully, (3)motor listrik, (4)V-belt, (5)tutup depan, (6)pisau perajang, (7)piringan, (8)saluran keluar, (9)tutup samping kiri, (10)hopper, (11)tutup piringan, (12)tutup atas, (13)poros tenah, (14)poros atas, (15)tutup belakang, (16)bearing, (17)tutup samping kanan

Prinsip kerja Mesin perajang cengkeh menggunakan sistem pneumatic:

1. Mesin perajang cengkeh ini akan bekerja ketika motor listrik dihidupkan maka akan berputar kemudian gerak putar dari mesin ditransmisikan ke puli 1, dari puli 1 ditransmisikan ke puli 2 dengan menggunakan belt untuk menggerakkan poros.

2. Jika poros 1 berputar maka akan menggerakkan puli 3 dan 4 dengan menggunakan belt untuk menggerakkan poros.

3. Setelah poros 2 berputar maka piringan tempat pisau akan berputar dan cengkeh yang dari hopper masuk ke bak pendorong kemudian siap untuk dirajang. Setelah cengkeh dirajang maka akan keluar melalui corong atau saluran keluar.

\subsection{Gaya Potong Cengkeh}

Perancangan gaya pisau perajang cengkeh pada mesin perajang cengkeh. Gaya pemotongan dihitung menggunakan persamaan 1 .

$F=A . f S$

Dimana $\mathrm{F}$ adalah gaya potong (sekali putar yang terjadi pada pisau perajang cengkeh), fs adalah tegangan geser bahan yang akan dipotong (cengkeh), A adalah luas penampang bahan yang akan dipotong. 
a. Torsi pemotongan

Dimana $\mathrm{F}$ adalah gaya potong dan $\mathrm{r}$ adalah jari-jari pisau

$T_{\text {pemotong }}=F \times r_{\text {pisau }}$

b. Daya pemotongan

Dimana $\mathrm{N}$ adalah putaran poros, $\mathrm{T}$ adalah torsi pemotongan, $\mathrm{V}$ adalah kecepatan, dan 60.102 adalah ketetapan.

$$
\mathrm{N}=\frac{T . V}{60.102}
$$

\subsection{Perancangan pisau pemotong}

Perancangan pisau pemotong jika satu kali putaran mesin perajang cengkeh.

a. Kapasitas pemotongan

Dimana Q adalah Kapasitas mesin

$$
\text { Maka: } \quad Q=\frac{50 \mathrm{Kg}}{\mathrm{Jam}} \times \frac{1 \mathrm{jam}}{60 \mathrm{menit}}
$$

b. Massa Pisau

Massa pisau di hitung menggunakan persamaan 3.

$$
W n=\text { L.I.t.y }
$$

Dimana $\mathrm{L}$ adalah Panjang mata pisau, I adalah lebar pisau, $\mathrm{t}$ adalah tebel pisau, y adalah berat jenis pisau

c. Massa Piringan

Massa piringan di hitung menggunakan persamaan 4.

$W n=d . r . t . y$

Dimana $\mathrm{d}$ adalah diameter, $\mathrm{r}$ adalah lebar piringan, $\mathrm{t}$ adalah tebal piringan, $\mathrm{y}$ adalah berat jenis piringan

d. Gaya tangensial pisau

Gayat angensial pisau di hitung menggunakan persamaan 5

$\mathrm{Ft}=\frac{W n}{g} \cdot \omega^{2} \cdot \mathrm{r}=\frac{W n}{g}\left(\frac{2 \cdot \pi \cdot r}{60}\right)^{2} \cdot \mathrm{r}$

Dimana Wn adalahmassa pisau $(\mathrm{kg}), \mathrm{n}$ adalah putaran poros (rpm), g adalah gaya gravitasi, $r$ adalah jari-jari lintasan potong.

e. Gaya tangensial pada piringan, dihitung menggunakan persamaan 6 .

$\mathrm{Ft}=\frac{W n}{g} \cdot \omega^{2} \cdot \mathrm{r}=\frac{W n}{g}\left(\frac{2 \cdot \pi \cdot r}{60}\right)^{2} \cdot \mathrm{r}$

Dimana Wn adalah massa piringan $(\mathrm{kg}), \mathrm{n}$ adalah putaran poros (rpm), $\mathrm{g}$ adalah gaya gravitasi, $r$ adalah jari-jari lintasan potong 


\subsection{Pemilihan Motor}

Pemilihan motor didasarkan pada daya pemotongan sebesar $0,9 \mathrm{Hp}$, kemudian daya rencana yang dibutuhkan dapat dihitung menggunakan persamaan 7 :

$$
\mathrm{N}_{\text {rencana }}=\frac{\mathrm{N} \text { potong }}{n_{\text {pully } \cdot n_{\text {bearing }}}}
$$

Dimana $\mathrm{N}_{\text {potong }}$ adalah daya yang dibutuhkan untuk pemotongan $=0,9 \mathrm{HP}, n_{\text {pully }}$ adalah efisiensi akibat reduksi pulley $=0,96$ (untuk pulley tipe V- belt), $\mathrm{n}_{\text {bearing }}=$ Efesiensi akibat reduksi bearing $=0,90$

\subsection{Perencanaan Transmisi}

Pada perancangan ini motor yang digunakan adalah motor dengan putaran $2500 \mathrm{rpm}$, untuk mereduksi putaran motor agar sesuai dengan putaran poros yaitu $1550 \mathrm{rpm}$ perlu menambahkan komponen lain yaitu puli dan sabuk.

a. Sabuk

$$
\mathrm{i}=\frac{n 1}{n 2}=\frac{d p 2}{d p 1}\left(1-\frac{s}{100}\right)
$$

Dimana $\mathrm{i}$ adalah perbandingan reduksi antara poros, $\mathrm{n} 1$ adalah putaran poros 1 (motor) $=2500 \mathrm{rpm}, \mathrm{n} 2-\mathrm{n} 3$ adalah putaran poros $2-3=2025 \mathrm{rpm}$, n4 adalah putaran poros pisau $=1550 \mathrm{rpm}, \mathrm{s}$ adalah faktor slip sabuk dengan pulley $(0,3=$ untuk bahan sabuk karet dan pulley baja).

b. Massa pully (Wp)

Bahan pully direncanakan dari besi cor kelabu (JIS G 5501) dengan lambang FC 20 , berat jenis

$$
\begin{aligned}
& (\rho)=7,4 \times 10 \frac{3 \mathrm{~kg}}{\mathrm{~m}^{3}} \\
& W p=\rho \times \mathrm{Vp}
\end{aligned}
$$

Dimana Vp adalah Volume pully, e adalah tebal pully = 0,012 $\mathrm{m}$ (untuk penampang sabuk A)

c. Kecepatan linier sabuk (V)

$$
\mathrm{V}=\frac{\pi \cdot d p 1 \cdot n 1}{60}
$$

d. Panjang sabuk (L)

Panjang sabuk di hitung menggunakan persamaan 11.

$$
\mathrm{L}_{1}=2 \mathrm{C}+\frac{\pi}{2}(\mathrm{dp} 1+\mathrm{dp} 2)+1 / 4 c\left(\mathrm{dp}^{2} 2-\mathrm{dp} 1\right)^{2}
$$




\subsection{Perhitungan Frame}

Perhitungan frame menggunakan data :

Panjang rangka $500 \mathrm{~mm}$

Rangka L uk. 40x40x2 mm

Pembebanan yang dihitung menggunakan shofware inventor 2019 dengan berat jenis baja $7.850 \mathrm{~g} / \mathrm{cm}^{3}$

Beban kapasitas cengkeh dan pembebanan $=50 \mathrm{~kg}=500 \mathrm{~N}$

$$
\mathrm{F}=500 \mathrm{~N}
$$

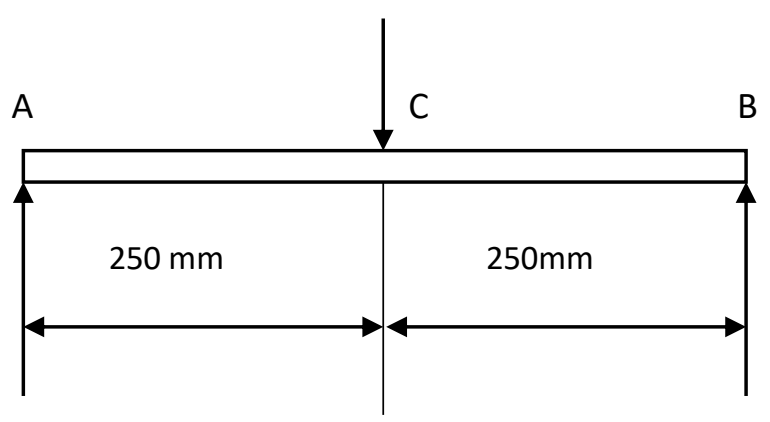

Gambar 3. gaya tekan pada frame perajang

a. Tegangan bengkok

Perhitungan tegangan bengkok menggunakan persamaan 12

$$
\sigma=\frac{M \cdot C}{I}
$$

Dimana M adalah Momen (62500 N), I adalah Momen inersia pada frame perajang cengkeh $\left(1333,3 \mathrm{~mm}^{2}\right.$

b. Tegangan geser

Perhitungan tegangan geser menggunakan persamaan 13.

$$
\tau g=\frac{V}{A}
$$

Di mana Tg adalah tegangan geser yang terjadi, $\mathrm{V}$ adalah beban maksimal, $\mathrm{A}$ adalah Luas permukaan

\section{c. Tegangan von mises}

Tegangan von mises di hitung menggunakan persamaan 14 .

$$
\tau \sigma \max =\frac{\sigma_{x}+\sigma_{y}}{2}+\sqrt{\left(\frac{\sigma_{x}-\sigma_{y}}{2}\right)^{2}+\left(\tau_{x y}\right)^{2}}
$$

Perhitungan manual tegangan von mises pada frame perajang cengkeh Sebesar 46,89 Mpa. 
Pada perancangan mesin perajang cengkeh menghasilkan nilai pada tabel 1.

Tabel 1.hasil dari perhutungan mesin perajang cengkeh

\begin{tabular}{ll}
\hline Perhitungan & Hasil \\
\hline Daya pemotongan & $0,9 \mathrm{Hp}$ \\
\hline Kapasitas pemotongan & $830 \mathrm{gr} / \mathrm{menit}$ \\
\hline Daya motor & $1 \mathrm{Hp}$ \\
\hline Diameter poros & $10,68 \mathrm{~mm}$ \\
\hline Tegangan geser frame & $0,3125 \mathrm{~N} / \mathrm{mm}^{2}$ \\
\hline Analisis Tegangan von mises & $46,89 \mathrm{Mpa}$ \\
\hline
\end{tabular}

\subsection{Von mises stress}

Analisis kegagalan menggunakan tegangan von mises pada rangka mesin perajang cengkeh. Analisis ini menggunakan metode elemenn hingga, hasil simulasi ditunjukkan pada gambar 4

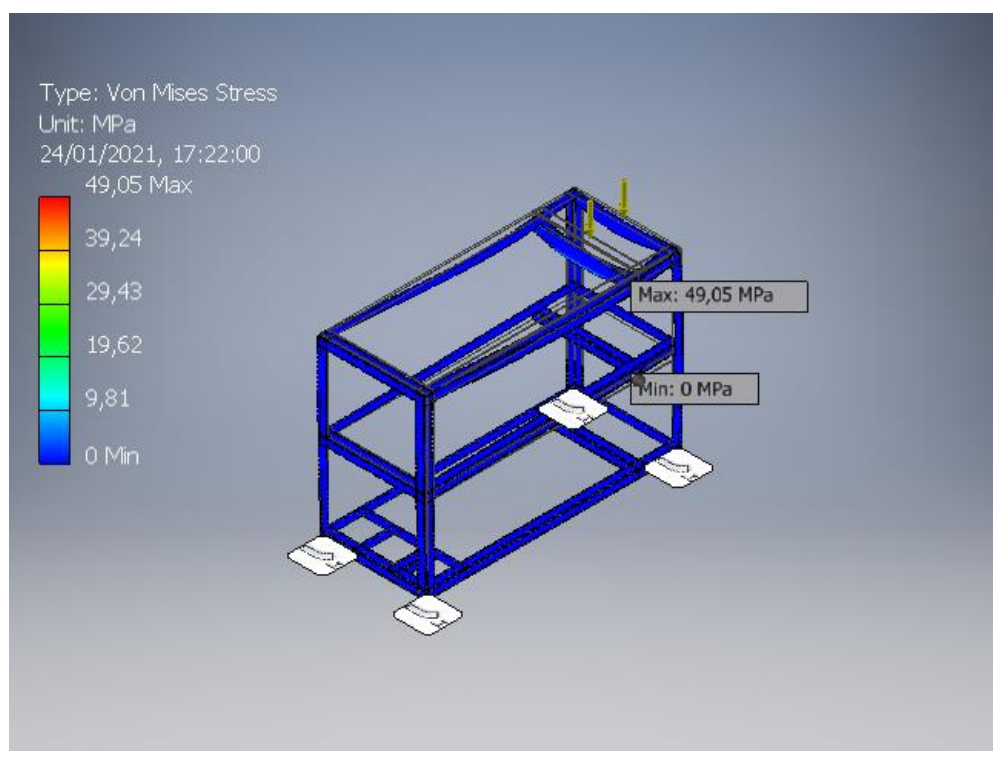

Gambar 4. Analisa von mises stress pada rangka mesin peranjang cengkeh

Pada gambar 4 menunjukan distribusi tegangan ke seluruh bagian geometri mesin perajang cengkeh mempunyai nilai von mesis stress sebesar 49,05 Mpa dan nilai von mises stress minimal 0 Mpa.

$$
\begin{aligned}
\text { Selisih }= & \frac{\text { perhitungan teori-simulasi }}{\text { simulasi }} \times 100 \% \\
& =\frac{46,89-49,05}{49,05} \times 100 \% \\
& =4,40 \%
\end{aligned}
$$

Hasil perhitungan analisis dan hasil simulasi selisihnya tidak signifikan sehingga analisis ini dapat dinyatakan valid. Kekuatan rangka dianggap mampu menahan beban pada mesin perajang cengkeh. 


\section{KESIMPULAN}

Berdasarkan dari hasil perhitungan dan desain mesin perajang cengkeh dapat disimpulkan dimensi mesin ukuran $1200 \mathrm{~mm}$ x $500 \mathrm{~mm}$ serta menggunakan penggerak motor listrik $1 \mathrm{HP}$ dan dari hasil perhitungan secara teoritis tegangan von mises pada rangka mesin perajang cengkeh sebesar 46,89 MPa dan secara simulasi tegangan von mises sebesar 49,05 MPa jadi selisih antara perhitungan teoritis dan simulasi sebesar $4,40 \%$.

\section{DAFTAR PUSTAKA}

[1] J. A. Rorong, 2008 "Uji Aktivitas Antioksidan Dari Daun Cengkeh ( Eugenia Carryophyllus ) Dengan Metode Dpph," vol. 1, no. 2,

[2] P. Rachmawati, 2019 , Rancang Bangun Mesin Perajang Singkong yang Memenuhi Aspek Ergonomis untuk Meningkatkan Produktivitas Pekerja, jurnal engine, vol. 3, no. 2, pp. 66-72,

[3] A. S. Fauzi, E. Predianto, and F. Rhohman, 2017, Mesin Pencacah Cengkeh, Jurnal ilmiah Rekayasa, vol. 10, no. 1, pp. 59-64.

[4] Anwar hidayat, Bambang Setyo, 2013, Perancangan Mesin perajang daun tembakau, jurnal daerah, vol. 6, no. 1, pp. 76 - 88.

[5] A. Rofeg, M. Kabib, 2018 "Analisa Tegangan Screw Conveyor Pada Mesin Pencampur Garam Dan Iodium Sesuai SNI 3556 Dengan Metode Elemen Hingga," Jurnal Simetris . Teknik Mesin, Elektro dan Ilmu Komputer., vol. 9, no. 2, pp. 935940, doi: 10.24176/simet.v9i2.2452.

[6] S. Kuntoro, M. Kabib, 2018, Analisis Kekuatan Dies Frame Link Pada Mesin Roll Pipa 2 In Penggerak Hidrolik Dengan Metode Elemen Hingga, Jurnal Simetris, Volume 9, Nomor 2, pp. 941 - 946.

[7] Hamdani Ahmad. Qomaruddin Qomaruddin. R. Winarso, M. Kabib. 2020. Perancangan Dan Simulasi Tegangan Rangka Mesin Pres Batako. Jurnal Crankshaft, Vol. 3, No. 2, Hal. 1-6.

[8] D. Aufana, M. Kabib, T. Hidayat, 2019, Perancangan Dan Simulasi Tegangan Frame Mesin Pengisian Curah Tembakau, Jurnal Crankshaft, Volume 2 No. 2, pp. 9 - 16. 